OPEN ACCESS

Edited by:

Rebecca Oelkrug,

University of Lübeck, Germany

Reviewed by:

Carola Waltraud Meyer, Max Planck Institute for Heart and Lung Research (MPG), Germany Pablo Torterolo, University of the Republic, Uruguay

${ }^{*}$ Correspondence: Matteo Cerr matteo.cerriunibo.it

Specialty section: This article was submitted to Integrative Physiology, a section of the journal Frontiers in Physiology

Received: 08 June 2017 Accepted: 11 August 2017 Published: 24 August 2017

Citation

Cerri M, Luppi M, Tupone D, Zamboni $G$ and Amici R (2017) REM Sleep and Endothermy: Potential Sites and Mechanism of a Reciprocal Interference. Front. Physiol. 8:624. doi: 10.3389/fphys.2017.00624

\section{REM Sleep and Endothermy: Potential Sites and Mechanism of a Reciprocal Interference}

\author{
Matteo Cerri *, Marco Luppi, Domenico Tupone, Giovanni Zamboni and Roberto Amici \\ Department of Biomedical and NeuroMotor Sciences, University of Bologna, Bologna, Italy
}

Numerous data show a reciprocal interaction between REM sleep and thermoregulation. During REM sleep, the function of thermoregulation appears to be impaired; from the other hand, the tonic activation of thermogenesis, such as during cold exposure, suppresses REM sleep occurrence. Recently, both the central neural network controlling REM sleep and the central neural network controlling thermoregulation have been progressively unraveled. Thermoregulation was shown to be controlled by a central "core" circuit, responsible for the maintenance of body temperature, modulated by a set of accessory areas. REM sleep was suggested to be controlled by a group of hypothalamic neurons overlooking at the REM sleep generating circuits within the brainstem. The two networks overlap in a few areas, and in this review, we will suggest that in such overlap may reside the explanation of the reciprocal interaction between REM sleep and thermoregulation. Considering the peculiar modulation of thermoregulation by REM sleep the result of their coincidental evolution, REM sleep may therefore be seen as a period of transient heterothermy.

\footnotetext{
Keywords: REM sleep, thermoregulation, heterothermy, median preoptic nucleus, periaqueductal gray, lateral parabrachial nucleus, orexin, melanin concentrating hormone
}

The primary function of rapid-eye movement sleep (REMS) is still unknown, but the finding that the daily amount of REMS is "homeostatically" regulated (Cerri et al., 2005; Amici et al., 2008) suggests that it may satisfy some primary physiological needs. Pioneering studies showed that REMS occurrence is depressed at an ambient temperature $(\mathrm{Ta})$ outside the thermoneutral range of the species (Parmeggiani and Rabini, 1967a), and thermoregulatory responses, such as shivering and panting, are suppressed during REMS (Parmeggiani and Rabini, 1967b). This thermoregulatory impairment has been confirmed by different studies (Parmeggiani, 2003; Heller, 2005). Also, since the direct warming and cooling of the preoptic area (POA) was shown to be inefficient in eliciting appropriate thermoregulatory responses during REMS, such an impairment was ascribed to a suspension in the central control of body temperature (Tb) (Parmeggiani et al., 1973, 1977; Glotzbach and Heller, 1976; Martelli et al., 2014).

However, the few studies on changes in POA neuronal thermosensitivity during sleep (Parmeggiani et al., 1983, 1986, 1987; Glotzbach and Heller, 1984; Alam et al., 1995) have not clarified the mechanisms of POA unresponsiveness during REMS. Consequently, investigations into the relationship between REMS and thermoregulation have been mostly phenomenal. A more mechanistic milieu has arisen from recent studies on thermoregulatory circuits (Morrison and Nakamura, 2011), and the critical role of the hypothalamus in sleep has been recognized (Saper et al., 2005). In this mini-review we will: (i) provide a brief data overview describing the interaction 
between REMS and thermoregulation; (ii) summarize the central networks regulating REMS and Tb and the areas in which they overlap and, (iii) suggest possible mechanisms of the reciprocal interaction between REMS and thermoregulation.

\section{REM SLEEP AND THERMOREGULATION}

Initial studies on the interaction between sleep and thermoregulation were carried out, in different species, at both low and high Tas (Parmeggiani and Rabini, 1970; Schmidek et al., 1972; Haskell et al., 1981; Sichieri and Schmidek, 1984). They showed that REMS amount plotted against Ta values took the shape of an inverted $U$ curve, with a maximum value moving in accordance with acclimation to Ta. In rats, the peak of REMS occurrence defined a thermoneutral zone (TNZ) that was narrower than that delimited by the minimal $\mathrm{O}_{2}$ consumption (Szymusiak and Satinoff, 1981). Thus, REMS occurrence is influenced by thermoregulation and declines at Tas beyond the TNZ limits. In accordance with this, not only REMS expression is higher at the circadian nadir of $\mathrm{Tb}$, but also the two rhythms are phase-locked in free-running conditions (Lee et al., 2009).

It is worth noting that, in the latter condition, REMS occurrence is preceded, during Wake and NREM sleep (NREMS), by postural adjustments that optimize thermal exchanges (Parmeggiani, 1980); the potential inhibition of REMS occurrence according to Ta belongs to the same repertoire of behavioral thermoregulation. In the rat, the efficacy of this mechanism is revealed by the observation that, during the acclimation to Tas close to the TNZ boundaries, REMS occurrence is initially reduced and then restored to control levels in about 1 week (Mahapatra et al., 2005; Kaushik et al., 2012).

Since endothermic homeotherms evolved with a $\mathrm{Tb}$ that was much closer to the upper than to the lower limit of their lethal core temperature, the interaction between REMS and thermoregulation has mostly been addressed within the wider span of cold defense mechanisms. In the rat, this approach showed that REMS is reduced proportionally to Ta and that the REMS debt is fully recovered, following the return to TNZ, through a mechanism based on the frequency rather than the duration of episodes (Cerri et al., 2005; Amici et al., 2008). This pattern, qualitatively described in early reports (Schmidek et al., 1972; Sichieri and Schmidek, 1984), appears to conform to the energetic constrains of polyphasic sleep in small mammals (Capellini et al., 2008).

Long-term selective REMS deprivation studies have been performed in the rat (Rechtschaffen et al., 1983). The results showed that animals progressively developed a severe hypothermia, caused by an increase in heat loss (Bergmann et al., 1989). This appeared to be counteracted by behavioral thermoregulation, since deprived animals were able to select progressively higher Tas in a thermal gradient (Prete et al., 1991), but not by an increase in metabolic rate, which was concomitant with an incremental hyperphagia. These results were further clarified by the finding, in REMS-deprived rats, of an increased expression of the uncoupling protein-1 in the brown adipose tissue (BAT) and a decrease in leptin secretion (Koban and
Swinson, 2005). Thus, it appears that a long-lasting deficiency of periods of central thermoregulatory unresponsiveness, represented by REMS, will progress to a malfunctioning of the different thermoeffector loops balancing $\mathrm{Tb}$ (Romanovsky, 2007).

The onset of REMS is characterized by an increase in hypothalamic temperature (Thy) (Kawamura and Sawyer, 1965), which is usually in the range of decimals of a degree and evident even outside the TNZ (Parmeggiani, 2003). This change was conditionally coupled to the increase in cerebral blood flow characterizing REMS (Franzini, 1992) until it was shown that it mainly depends on an larger increase in the flow from vertebral arteries compared to that from carotid arteries, the former circle supplying the brain with warmer blood than the latter (Azzaroni and Parmeggiani, 1993).

The thermal irrelevance of the Thy increase during REMS episodes contrasts with its strictly controlled decrease, during NREMS episodes leading to REMS occurrence (Parmeggiani et al., 1975). With respect to this, a quantitative study on the slope of that decrease showed the possibility to predict the onset of REMS within a 1 min interval (Capitani et al., 2005).

The thermal irresponsiveness of POA, decrease in the overall $\mathrm{O}_{2}$ consumption and increase in the overall heat loss (Roussel and Bittel, 1979; Schmidek et al., 1983), probably due to changes in peripheral vasomotion in opposition to a homeothermic control of Tb (Parmeggiani et al., 1977; Franzini et al., 1982; Alfoldi et al., 1990), support the view that REMS is a poikilothermic state, while Wake and NREMS remain homeothermic (Parmeggiani, 2003).

By taking into account the autonomic irregularities associated with REMS (Parmeggiani, 1980; Amici et al., 2014) this dichotomy may be extended to systemic physiological regulations, indicating a poikilostatic control for REMS and the permanence of a homeostatic control for Wake and NREMS (Parmeggiani, 2003). According to this view, POA thermal irresponsiveness depends on an impairment of diencephalic integrative activity. Thus, physiological regulation during REMS should mainly operate through a brainstem reflex activity, destitute of the hypothalamic control (Parmeggiani, 2003). However, hypothalamic osmoregulation, which is phylogenetically older than thermoregulation, is not impaired during REMS (Luppi et al., 2010), and REMS occurrence is hardly affected by a long-lasting water deprivation (Martelli et al., 2012). These results raise the possibility that the distinctive trait of REMS is the development of a poikilothermic condition, and this may be the reason why REMS occurrence is so intensely influenced by thermoregulation.

\section{THE CENTRAL CIRCUITS CONTROLLING REM SLEEP AND THERMOREGULATION}

\section{The Central Network Controlling REM Sleep}

The neural network controlling REMS onset was initially outlined in the cat (Jouvet, 1962) and, later, in the rat (Luppi et al., $2014,2017)$. In the cat, a central role in REMS generation has 
been attributed to pontine cholinoceptive/cholinergic neurons (Vanni-Mercier et al., 1989; Sakai and Koyama, 1996). In the rat, the crucial role of pontine structures in REMS generation has been confirmed, and general agreement has been reached regarding the prominent role of REMS-on glutamatergic neurons of the sublaterodorsal tegmental nucleus (SLD) (Luppi et al., 2014, 2017). Projections from SLD have been shown to activate neural networks underlying both brain cortical and somatic hallmarks of REMS (Luppi et al., 2014, 2017).

SLD neurons receive a tonic excitatory glutamatergic input from different brain areas and are kept inhibited during Wake and NREMS by projections from REMS-off neurons of the ventrolateral periaqueductal gray (VlPAG) and the dorsal deep mesencephalic reticular nuclei (dDPMe) (Luppi et al., 2014, 2017). VlPAG/dDPMe REMS-off neurons are excited by both orexin neurons in the lateral hypothalamus (LH) and monoaminergic neurons in the brainstem and tuberomammillary wake-promoting areas.

The inhibition of these VlPAG/dDPMe REMS-off neurons is apparently crucial for REMS onset. Active inhibition is promoted by a sub-population of VlPAG GABAergic REMS-on neurons, while disfacilitation is due to the suppression of firing, during REMS, of monoaminergic wake-promoting neurons, to which GABAergic REMS-on VIPAG neurons also send their terminals. It has been proposed that further inhibitory inputs arise from ascending GABAergic projections from the medulla in both rats (Luppi et al., 2014, 2017) and mice (Weber et al., 2015).

A crucial role in the inhibition of VlPAG/dDPMe REMSoff neurons is played by REMS-on neurons of the posterior hypothalamus, including $\mathrm{LH}$, zona incerta, and perifornical hypothalamus, many of which release GABAand/or the peptide melanin-concentrating hormone (MCH) (Luppi et al., 2014, 2017). In fact, this group of neurons is considered the "master generator" of REMS (Luppi et al., 2014). The central role of the hypothalamic $\mathrm{MCH} / \mathrm{GABAergic}$ neurons in REMS occurrence has been underlined by optogenetic and chemogenetic studies in rats (Jego et al., 2013) and mice (Vetrivelan et al., 2016), respectively. $\mathrm{MCH}$ neurons, inhibited by monoaminergic wakepromoting neurons, may also contribute to the active inhibition of orexin neurons in the LH during REMS.

At a preoptic-hypothalamic level, the median preoptic nucleus $(\mathrm{MnPO})$ and the ventrolateral preoptic nucleus (VLPO) play a role in REMS regulation (Gvilia et al., 2006; Dentico et al., 2009). In both structures, the degree of cellular activity appears to be related to the homeostatic need for REMS, which, increases during REMS deprivation and decreases during the following REMS rebound. It has been suggested that both structures are part of the network for the switching-off of the brainstem and hypothalamic wake-promoting centers when sleep need is increased, but the MnPO has been shown to have a closer link with REMS regulation (Szymusiak and McGinty, 2008; McKinley et al., 2015). A similar REMS-related pattern has been found at the pontine level in the Lateral Parabrachial Nucleus (IPBN), largely active during both REMS deprivation and the following REMS rebound (Verret et al., 2005).

\section{The Central Network Controlling Thermoregulation}

Research in thermoregulation has led to a better definition of the neural pathways through which cutaneous thermal receptors activate BAT thermogenesis, as well as shivering thermogenesis, and cutaneous vasoconstriction (CVC) for heat retention, necessary for cold defense (Cano et al., 2003; Nakamura and Morrison, 2007, 2008, 2010, 2011; Morrison and Nakamura, 2011; Morrison et al., 2012).

Cold and warm signals from the skin are transmitted, through glutamatergic second order ascending neurons from the dorsal horn to the externolateral- (el) and dorsolateral- (dl) PBN neurons, respectively. From here, elPBN glutamatergic neurons convey the cold thermal signal to the GABAergic Median preoptic (MnPO) neurons (Tan et al., 2016), which in turn inhibit the warm-sensitive GABAergic neurons within the medial preoptic (MPO) projecting to the dorso-medial hypothalamus (DMH) and raphe pallidus (RPa). This leads to an increased activity of thermogenesis-promoting neurons in the DMH, which provide the main excitatory drive for the rostral $\mathrm{RPa}(\mathrm{rRPa})$ premotor neurons with consequent activation of thermogenesis (Morrison et al., 1999; Cerri et al., 2010). Alternatively, warm thermal signals retransmitted by dlPBN glutamatergic neurons activate the $\mathrm{MnPO}$ glutamatergic neurons, which in turn activate MPO GABAergic neurons projecting to the DMH and rRPa. This leads to an inhibition of thermogenesis-promoting neurons in the $\mathrm{DMH}$, reducing the excitatory drive to the rRPa premotor neurons. The inhibition of RPa neurons increases thermal dissipation and leads to a reduction in body temperature (Cerri et al., 2010, 2013).

The thermoregulatory network sends its branches to several brain areas that control metabolic, cardiovascular, osmolar and respiratory functions and, conversely, receives feedback from these areas, thus modulating thermoregulatory responses (Morrison et al., 2014). Among these areas, the role of the LH and the PAG is of particular interest in the context of this review.

Two relevant populations of neurons that modulate thermoregulation are located within the LH: orexin neurons and $\mathrm{MCH}$ neurons. Orexin neurons send direct projections to the rRPa (Oldfield et al., 2002; Berthoud et al., 2005; Tupone et al., 2011), are directly involved in the modulation of BAT thermogenesis (Tupone et al., 2011; Luong and Carrive, 2012), are indispensable to mediate the prostaglandin E2-induced fever, and are necessary for the defense against environmental cooling in mice (Takahashi et al., 2013). MCH signal deficiency has been shown to increase Tb (Ahnaou et al., 2011; Takase et al., 2014).

PAG neurons receive projections from the main thermoregulatory hypothalamic nuclei (Rizvi et al., 1992; Yoshida et al., 2005) and project directly to the rRPa (Hermann et al., 1997) and, multi-synaptically, to BAT (Cano et al., 2003), mostly from the ventromedial and the ventrolateral regions, respectively. The caudal portion of the lateral PAG contains BAT sympatho-excitatory neurons (Chen et al., 2002; Nakamura and Morrison, 2007), whereas the rostral PAG contains BAT sympatho-inhibitory neurons (Rathner and Morrison, 2006). 


\section{POTENTIAL SITES AND MECHANISMS AT THE BASE OF THE INTERACTION BETWEEN REM SLEEP AND THERMOREGULATION}

The tight reciprocal link between REMS and thermoregulation suggests the existence of mechanisms underlying this interaction at the level of the brain areas shared by the two regulatory networks. In fact, it is noteworthy that the sleep network and the thermoregulation network overlap in some brain areas (Figure 1). This overlap is particularly evident in the case of the LH, where two populations of wake-promoting neurons, expressing orexin (Adamantidis et al., 2007) or GABA (Venner et al., 2016), are intermingled with a population of REMSpromoting neurons expressing GABA and MCH (Hanriot et al., 2007). $\mathrm{MCH}$ neurons are also segregated from the orexin neurons (Kerman et al., 2007), and send reciprocal connections to each other (Guan et al., 2002). The entire area also has relevant effects on thermoregulation and behavioral state regulation when activated (Cerri and Morrison, 2005; Di Cristoforo et al., 2015), or inhibited (Cerri et al., 2014). In particular, the LH inhibition by the local delivery of the GABA-A agonist muscimol led to REMS suppression in rats (Clement et al., 2012; Cerri et al., 2014).

Another overlap between the two networks occurs at the POA level, in particular, the MnPO. The MnPO is a very important integrative site for homeostatic function, since it receives inputs from different sensory pathways and contains osmoresponsive, thermoresponsive, and sleep-related neurons, which, to some extent, reciprocally interact (McKinley et al., 2015). Intrinsic MnPO GABAergic neurons, which are activated by projections from the elPBN might directly or indirectly inhibit the REMS-related neurons in the MnPO, contributing to Wake enhancement and REMS suppression at a low Ta.

A further possible site of overlap between REMS regulation and thermoregulation is the VlPAG. On one hand, a consistent number of either REMS-off or REMS-on neurons have been found in VlPAG (Sapin et al., 2009). On the other hand, neurons from this region directly project to the $\mathrm{RPa}$ (Hermann et al., 1997; Cano et al., 2003), some of which are able to indirectly promote BAT activity (Chen et al., 2002; Nakamura and Morrison, 2007). However, these neurons appear to be differently controlled. In fact, while REMS-off neurons are apparently kept active by orexinergic and monoaminergic afferents (Luppi et al., 2014, 2017), thermoregulatory neurons apparently receive inputs from the $\mathrm{DMH}$ /dorsal hypothalamic area (Yoshida et al., 2005) and the MPO (Rizvi et al., 1992). As discussed by others (Martelli et al., 2013), a further possible site of overlap can be found at the level of the IPBN, since IPBN neurons may influence REMS occurrence via direct projections to the SLD (Boissard et al., 2003).

\section{CONCLUSIONS}

A way to consider changes in the activity of MnPO in REMS deprivation and recovery (Gvilia et al., 2006; Dentico et al., 2009) is that this nucleus belongs to a preoptic set which is thought to form, with the DMH, a visceromotor pattern generator (HVPG)

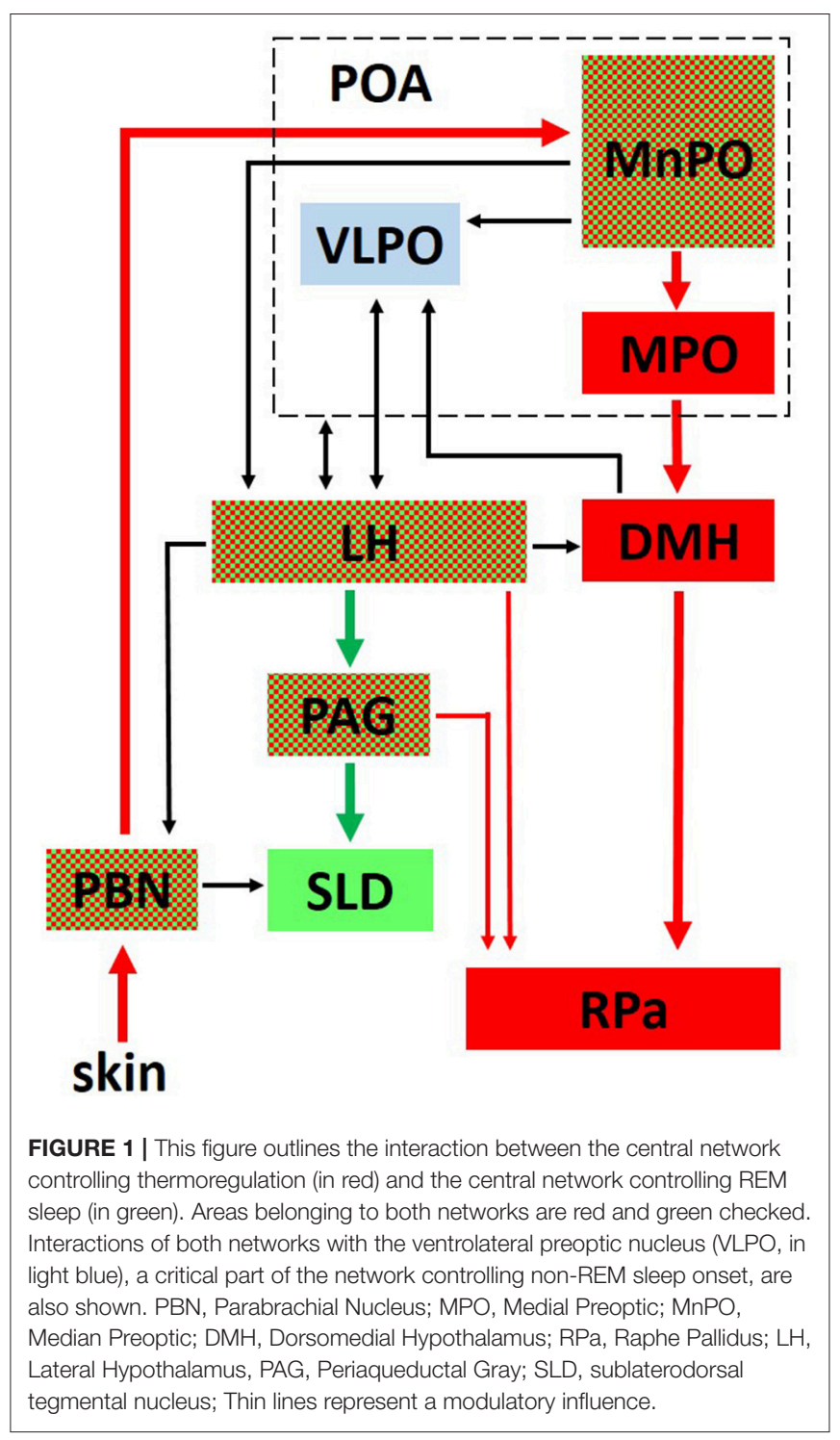

(Thompson and Swanson, 2003). As suggested by the normality of fluid regulation (Luppi et al., 2010; Martelli et al., 2012), the thermal irresponsiveness of POA may change the visceromotor response patterns of HPVG.

The clamping of Thy, during REMS, by a diathermic warming of the thermally irresponsive POA, doubled episode duration even at a Ta well below the lower limit of TNZ (Parmeggiani et al., 1974), and this extra REMS was fully accounted for within deprivation-recovery processes (Parmeggiani et al., 1980). This increase in REMS duration may be interpreted as a direct thermal effect on sleep-regulating circuits, whereas hypothermia has the opposite effect (Jones et al., 2008; Del Vecchio et al., 2014). However, its striking efficacy may, alternatively, be viewed as a sign that Thy is monitored by POA before REMS onset, and by the DMH subdivision of HPVG during its occurrence. Along these lines, the diathermic warming of POA did not change c-FOS expression in that area, but suppressed a c-FOS increase induced in $\mathrm{DMH}$ by previous cold exposure (Yoshida 
et al., 2002). The potential role for $\mathrm{DMH}$ in the peculiar thermoregulatory set of REMS is further supported by the finding that a transection separating POA from DMH transforms the input of peripheral thermoreceptors into a response, by thermal effectors, that is directly proportional to Ta (inverted thermoregulation) (Tupone et al., 2017).

Thus, taken together, these results suggest that REMS may be considered as a transient heterothermic state fulfilling, within the far-reaching protection of a rest period, specific needs of endotherms brain activity, rather than energy saving. This view appears in line with the hypothesis of a coevolution of REMS and thermoregulation (Lee Kavanau, 2002) and the observation of an occurrence of REMS-like episodes in hibernating lemurs only at the highest Ta still compatible with torpor (Krystal et al., 2013; Blanco et al., 2016).

On these bases, the interplay between REMS and thermoregulation may be linked to the simultaneous evolution of the two functions, and the sharing of regulatory areas may be the results of some evolutionary constraint in

\section{REFERENCES}

Adamantidis, A. R., Zhang, F., Aravanis, A. M., Deisseroth, K., and de Lecea, L. (2007). Neural substrates of awakening probed with optogenetic control of hypocretin neurons. Nature 450, 420-424. doi: 10.1038/nature06310

Ahnaou, A., Dautzenberg, F. M., Huysmans, H., Steckler, T., and Drinkenburg, W. H. (2011). Contribution of melanin-concentrating hormone (MCH1) receptor to thermoregulation and sleep stabilization: evidence from MCH1 (-/-) mice. Behav. Brain Res. 218, 42-50. doi: 10.1016/j.bbr.2010.11.019

Alam, M. N., McGinty, D., and Szymusiak, R. (1995). Preoptic/anterior hypothalamic neurons: thermosensitivity in rapid eye movement sleep. Am. J. Physiol. 269(5 Pt 2), R1250-R1257.

Alfoldi, P., Rubicsek, G., Cserni, G., and Obal, F. Jr. (1990). Brain and core temperatures and peripheral vasomotion during sleep and wakefulness at various ambient temperatures in the rat. Pflugers Arch. 417, 336-341. doi: 10.1007/BF00371001

Amici, R., Bastianini, S., Berteotti, C., Cerri, M., Del Vecchio, F., Lo Martire, V., et al. (2014). Sleep and bodily functions: the physiological interplay between body homeostasis and sleep homeostasis. Arch. Ital. Biol. 152, 66-78. doi: 10.12871/000298292014232

Amici, R., Cerri, M., Ocampo-Garces, A., Baracchi, F., Dentico, D., Jones, C. A., et al. (2008). Cold exposure and sleep in the rat: REM sleep homeostasis and body size. Sleep 31, 708-715. doi: 10.1093/sleep/31.5.708

Azzaroni, A., and Parmeggiani, P. L. (1993). Mechanisms underlying hypothalamic temperature changes during sleep in mammals. Brain Res. 632, 136-142. doi: 10.1016/0006-8993(93)91148-L

Bergmann, B. M., Everson, C. A., Kushida, C. A., Fang, V. S., Leitch, C. A., Schoeller, D. A., et al. (1989). Sleep deprivation in the rat: V. Energy use and mediation. Sleep 12, 31-41. doi: 10.1093/sleep/12.1.31

Berthoud, H. R., Patterson, L. M., Sutton, G. M., Morrison, C., and Zheng, H. (2005). Orexin inputs to caudal raphe neurons involved in thermal, cardiovascular, and gastrointestinal regulation. Histochem. Cell Biol. 123, 147-156. doi: 10.1007/s00418-005-0761-x

Blanco, M. B., Dausmann, K. H., Faherty, S. L., Klopfer, P., Krystal, A. D., Schopler, R., et al. (2016). Hibernation in a primate: does sleep occur? R. Soc. Open Sci. 3:160282. doi: 10.1098/rsos.160282

Boissard, R., Fort, P., Gervasoni, D., Barbagli, B., and Luppi, P.H. (2003). Localization of the GABAergic and non-GABAergic neurons projecting to the sublaterodorsal nucleus and potentially gating paradoxical sleep onset. Eur. J. Neurosci. 18, 1627-1639. doi: 10.1046/j.1460-9568.2003.02861.x

Cano, G., Passerin, A. M., Schiltz, J. C., Card, J. P., Morrison, S. F., and Sved, A. F. (2003). Anatomical substrates for the central control of sympathetic outflow terms of developmental physiology. Thus, the study of the interaction between REMS and thermoregulation may open new perspectives on how the two functions developed and shed light on the yet unknown purpose of REMS.

\section{AUTHOR CONTRIBUTIONS}

This manuscript is the result of the common effert of MC, ML, DT, GZ, and RA. All the authors contributed to the development of the manuscript.

\section{FUNDING}

Funding for this paper came from the University of Bologna (RFO).

\section{ACKNOWLEDGMENTS}

The authors thank Mrs. Melissa Stott for reviewing the English.

to interscapular adipose tissue during cold exposure. J. Comp. Neurol. 460, 303-326. doi: 10.1002/cne.10643

Capellini, I., Nunn, C. L., McNamara, P., Preston, B. T., and Barton, R. A. (2008), Energetic constraints, not predation, influence the evolution of sleep patterning in mammals. Funct. Ecol. 22, 847-853. doi: 10.1111/j.1365-2435.2008.01449.x

Capitani, P., Cerri, M., Amici, R., Baracchi, F., Jones, C. A., Luppi, M., et al. (2005). Changes in EEG activity and hypothalamic temperature as indices for non-REM sleep to REM sleep transitions. Neurosci. Lett. 383, 182-187. doi: 10.1016/j.neulet.2005.04.009

Cerri, M., and Morrison, S. F. (2005). Activation of lateral hypothalamic neurons stimulates brown adipose tissue thermogenesis. Neuroscience 135, 627-638. doi: 10.1016/j.neuroscience.2005.06.039

Cerri, M., Del Vecchio, F., Mastrotto, M., Luppi, M., Martelli, D., Perez, E., et al. (2014). Enhanced slow-wave EEG activity and thermoregulatory impairment following the inhibition of the lateral hypothalamus in the rat. PLOS ONE 9:e112849. doi: 10.1371/journal.pone.0112849

Cerri, M., Mastrotto, M., Tupone, D., Martelli, D., Luppi, M., Perez, E., et al. (2013). The inhibition of neurons in the central nervous pathways for thermoregulatory cold defense induces a suspended animation state in the rat. J. Neurosci. 33, 2984-2993. doi: 10.1523/JNEUROSCI.3596-12.2013

Cerri, M., Ocampo-Garces, A., Amici, R., Baracchi, F., Capitani, P., Jones, C. A., et al. (2005). Cold exposure and sleep in the rat: effects on sleep architecture and the electroencephalogram. Sleep 28, 694-705. doi: 10.1093/sleep/28.6.694

Cerri, M., Zamboni, G., Tupone, D., Dentico, D., Luppi, M., Martelli, D., et al. (2010). Cutaneous vasodilation elicited by disinhibition of the caudal portion of the rostral ventromedial medulla of the free-behaving rat. Neuroscience 165, 984-995. doi: 10.1016/j.neuroscience.2009.10.068

Chen, X. M., Nishi, M., Taniguchi, A., Nagashima, K., Shibata, M., and Kanosue, K. (2002). The caudal periaqueductal gray participates in the activation of brown adipose tissue in rats. Neurosci. Lett. 331, 17-20. doi: 10.1016/S0304-3940(02)00757-7

Clement, O., Sapin, E., Libourel, P. A., Arthaud, S., Brischoux, F., Fort, P., et al. (2012). The lateral hypothalamic area controls paradoxical (REM) sleep by means of descending projections to brainstem GABAergic neurons. J. Neurosci. 32, 16763-16774. doi: 10.1523/JNEUROSCI.1885-12.2012

Del Vecchio, F., Nalivaiko, E., Cerri, M., Luppi, M., and Amici, R. (2014), Provocative motion causes fall in brain temperature and affects sleep in rats. Exp. Brain Res. 232, 2591-2599. doi: 10.1007/s00221-014-3899-8

Dentico, D., Amici, R., Baracchi, F., Cerri, M., Del Sindaco, E., Luppi, M., et al. (2009). c-Fos expression in preoptic nuclei as a marker of sleep rebound in the rat. Eur. J. Neurosci. 30, 651-661. doi: 10.1111/j.1460-9568.2009. 06848.x 
Di Cristoforo, A., Cerri, M., Del Vecchio, F., Hitrec, T., Luppi, M., Perez, E., et al. (2015). Wake-sleep, thermoregulatory, and autonomic effects of cholinergic activation of the lateral hypothalamus in the rat: a pilot study. Arch. Ital. Biol. 153, 67-76. doi: 10.12871/000398292015232

Franzini, C. (1992). Brain metabolism and blood flow during sleep. J. Sleep Res.. 1, 3-16. doi: 10.1111/j.1365-2869.1992.tb00002.x

Franzini, C., Cianci, T., Lenzi, P., and Guidalotti, P. L. (1982). Neural control of vasomotion in rabbit ear is impaired during desynchronized sleep. Am. J. Physiol. 243, R142-146.

Glotzbach, S. F., and Heller, H. C. (1976). Central nervous regulation of body temperature during sleep. Science 194, 537-539. doi: 10.1126/science.973138

Glotzbach, S. F., and Heller, H. C. (1984). Changes in the thermal characteristics of hypothalamic neurons during sleep and wakefulness. Brain Res. 309, 17-26. doi: 10.1016/0006-8993(84)91006-0

Guan, J. L., Uehara, K., Lu, S., Wang, Q. P., Funahashi, H., Sakurai, T., et al. (2002). Reciprocal synaptic relationships between orexin- and melanin-concentrating hormone-containing neurons in the rat lateral hypothalamus: a novel circuit implicated in feeding regulation. Int. J. Obes. Relat. Metab. Disord. 26, 1523-1532. doi: 10.1038/sj.ijo.0802155

Gvilia, I., Xu, F., McGinty, D., and Szymusiak, R. (2006). Homeostatic regulation of sleep: a role for preoptic area neurons. J. Neurosci. 26, 9426-9433. doi: 10.1523/JNEUROSCI.2012-06.2006

Hanriot, L., Camargo, N., Courau, A. C., Leger, L., Luppi, P. H., and Peyron, C. (2007). Characterization of the melanin-concentrating hormone neurons activated during paradoxical sleep hypersomnia in rats. J. Comp. Neurol. 505, 147-157. doi: 10.1002/cne.21482

Haskell, E. H., Palca, J. W., Walker, J. M., Berger, R. J., and Heller, H. C. (1981). The effects of high and low ambient temperatures on human sleep stages. Electroencephalogr. Clin. Neurophysiol. 51, 494-501. doi: 10.1016/0013-4694(81)90226-1

Heller, H. C. (2005). "Temperature, Thermoregulation, and Sleep," in Principle and Practice of Sleep Medicine, eds. M. H. Kryger, T. Roth, and W. E. Dement (Philadelphia, PA: Wb Saunders), 292-304.

Hermann, D. M., Luppi, P. H., Peyron, C., Hinckel, P., and Jouvet, M. (1997). Afferent projections to the rat nuclei raphe magnus, raphe pallidus and reticularis gigantocellularis pars alpha demonstrated by iontophoretic application of choleratoxin (subunit b). J. Chem. Neuroanat. 13, 1-21. doi: 10.1016/S0891-0618(97)00019-7

Jego, S., Glasgow, S. D., Herrera, C. G., Ekstrand, M., Reed, S. J., Boyce, R., et al. (2013). Optogenetic identification of a rapid eye movement sleep modulatory circuit in the hypothalamus. Nat. Neurosci. 16, 1637-1643. doi: $10.1038 / \mathrm{nn} .3522$

Jones, C. A., Perez, E., Amici, R., Luppi, M., Baracchi, F., Cerri, M., et al. (2008). Lithium affects REM sleep occurrence, autonomic activity and brain second messengers in the rat. Behav. Brain Res. 187, 254-261. doi: 10.1016/j.bbr.2007.09.017

Jouvet, M. (1962). Research on the neural structures and responsible mechanisms in different phases of physiological sleep. Arch. Ital. Biol. 100, 125-206.

Kaushik, M. K., Kumar, V. M., and Mallick, H. N. (2012). Hypothalamic temperature: a key regulator in homeostatic restoration of sleep during chronic cold exposure in rats. Indian J. Physiol. Pharmacol. 56, 301-313.

Kawamura, H., and Sawyer, C. H. (1965). Elevation in brain temperature during paradoxical sleep. Science 150, 912-913. doi: 10.1126/science.150.3698.912

Kerman, I. A., Bernard, R., Rosenthal, D., Beals, J., Akil, H., and Watson, S. J. (2007). Distinct populations of presympathetic-premotor neurons express orexin or melanin-concentrating hormone in the rat lateral hypothalamus. $J$. Comp. Neurol. 505, 586-601. doi: 10.1002/cne.21511

Koban, M., and Swinson, K. L. (2005). Chronic REM-sleep deprivation of rats elevates metabolic rate and increases UCP1 gene expression in brown adipose tissue. Am. J. Physiol. Endocrinol. Metab. 289, E68-E74. doi: 10.1152/ajpendo.00543.2004

Krystal, A. D., Schopler, B., Kobbe, S., Williams, C., Rakatondrainibe, H., Yoder, A. D., et al. (2013). The relationship of sleep with temperature and metabolic rate in a hibernating primate. PLoS ONE 8:e69914. doi: 10.1371/journal.pone.0069914

Lee Kavanau, J. (2002). REM and NREM sleep as natural accompaniments of the evolution of warm-bloodedness. Neurosci. Biobehav. Rev. 26, 889-906. doi: 10.1016/S0149-7634(02)00088-X
Lee, M. L., Swanson, B. E., and de la Iglesia, H. O. (2009). Circadian timing of REM sleep is coupled to an oscillator within the dorsomedial suprachiasmatic nucleus. Curr. Biol. 19, 848-852. doi: 10.1016/j.cub.2009.03.051

Luong, L. N., and Carrive, P. (2012). Orexin microinjection in the medullary raphe increases heart rate and arterial pressure but does not reduce tail skin blood flow in the awake rat. Neuroscience 202, 209-217. doi: 10.1016/j.neuroscience.2011.11.073

Luppi, M., Martelli, D., Amici, R., Baracchi, F., Cerri, M., Dentico, D., et al. (2010). Hypothalamic osmoregulation is maintained across the wake-sleep cycle in the rat. J. Sleep Res. 19, 394-399. doi: 10.1111/j.1365-2869.2009.00810.x

Luppi, P. H., Adamantidis, A. R., and Fort, P. (2014). "The neurophysiology and neurobiology of sleep," in Sleep Medicine Textbook, eds C. Basssetti, P. Dogasz, and P. Peigneux (Regensburg: European Sleep Research Society), 3-11.

Luppi, P. H., Peyron, C., and Fort, P. (2017). Not a single but multiple populations of GABAergic neurons control sleep. Sleep Med. Rev. 32, 85-94. doi: 10.1016/j.smrv.2016.03.002

Mahapatra, A. P., Mallick, H. N., and Kumar, V. M. (2005). Changes in sleep on chronic exposure to warm and cold ambient temperatures. Physiol. Behav. 84, 287-294. doi: 10.1016/j.physbeh.2004.12.003

Martelli, D., Luppi, M., Cerri, M., Tupone, D., Mastrotto, M., Perez, E., et al. (2014). The direct cooling of the preoptic-hypothalamic area elicits the release of thyroid stimulating hormone during wakefulness but not during REM sleep. PLoS ONE 9:e87793. doi: 10.1371/journal.pone.0087793

Martelli, D., Luppi, M., Cerri, M., Tupone, D., Perez, E., Zamboni, G., et al. (2012). Waking and sleeping following water deprivation in the rat. PLoS ONE 7:e46116. doi: 10.1371/journal.pone.0046116

Martelli, D., Stanic, D., and Dutschmann, M. (2013). The emerging role of the parabrachial complex in the generation of wakefulness drive and its implication for respiratory control. Respir. Physiol. Neurobiol. 188, 318-323. doi: 10.1016/j.resp.2013.06.019

McKinley, M. J., Yao, S. T., Uschakov, A., McAllen, R. M., Rundgren, M., and Martelli, D. (2015). The median preoptic nucleus: front and centre for the regulation of body fluid, sodium, temperature, sleep and cardiovascular homeostasis. Acta Physiol. 214, 8-32. doi: 10.1111/apha.12487

Morrison, S. F., Madden, C. J., and Tupone, D. (2012). Central control of brown adipose tissue thermogenesis. Front. Endocrinol. 3:5. doi: $10.3389 /$ fendo.2012.00005

Morrison, S. F., Madden, C. J., and Tupone, D. (2014). Central neural regulation of brown adipose tissue thermogenesis and energy expenditure. Cell Metab. 19, 741-756. doi: 10.1016/j.cmet.2014.02.007

Morrison, S. F., and Nakamura, K. (2011). Central neural pathways for thermoregulation. Front. Biosci. 16, 74-104. doi: 10.2741/3677

Morrison, S. F., Sved, A. F., and Passerin, A. M. (1999). GABA-mediated inhibition of raphe pallidus neurons regulates sympathetic outflow to brown adipose tissue. Am. J. Physiol. 276(2 Pt 2), R290-R297.

Nakamura, K., and Morrison, S. F. (2007). Central efferent pathways mediating skin cooling-evoked sympathetic thermogenesis in brown adipose tissue. Am. J. Physiol. Regul. Integr. Comp. Physiol. 292, R127-136. doi: 10.1152/ajpregu.00427.2006

Nakamura, K., and Morrison, S. F. (2008). A thermosensory pathway that controls body temperature. Nat. Neurosci. 11, 62-71. doi: 10.1038/nn2027

Nakamura, K., and Morrison, S. F. (2010). A thermosensory pathway mediating heat-defense responses. Proc. Natl. Acad. Sci. U.S.A. 107, 8848-8853. doi: $10.1073 /$ pnas. 0913358107

Nakamura, K., and Morrison, S. F. (2011). Central efferent pathways for cold-defensive and febrile shivering. J. Physiol. 589(Pt 14), 3641-3658. doi: 10.1113/jphysiol.2011.210047

Oldfield, B. J., Giles, M. E., Watson, A., Anderson, C., Colvill, L. M., and McKinley, M. J. (2002). The neurochemical characterisation of hypothalamic pathways projecting polysynaptically to brown adipose tissue in the rat. Neuroscience 110, 515-526. doi: 10.1016/S0306-4522(01)00555-3

Parmeggiani, P. L. (1980). Behavioral phenomenology of sleep (somatic and vegetative). Experientia 36, 6-11. doi: 10.1007/BF020 03941

Parmeggiani, P. L. (2003). Thermoregulation and sleep. Front. Biosci. 8, s557-s567. doi: $10.2741 / 1054$

Parmeggiani, P. L., Agnati, L. F., Zamboni, G., and Cianci, T. (1975). Hypothalamic temperature during the sleep cycle at different ambient 
temperatures. Electroencephalogr. Clin. Neurophysiol. 38, 589-596. doi: 10.1016/0013-4694(75)90159-5

Parmeggiani, P. L., and Rabini, C. (1967a). Phases of sleep and environmental temperature. Helv. Physiol. Pharmacol. Acta 25, CR214-216. doi: 10.1016/0006-8993(67)90139-4

Parmeggiani, P. L., and Rabini, C. (1967b). Shivering and panting during sleep. Brain Res. 6, 789-791.

Parmeggiani, P. L., and Rabini, C. (1970). Sleep and environmental temperature. Arch. Ital. Biol. 108, 369-387.

Parmeggiani, P. L., Azzaroni, A., Cevolani, D., and Ferrari, G. (1983). Responses of anterior hypothalamic-preoptic neurons to direct thermal stimulation during wakefulness and sleep. Brain Res. 269, 382-385. doi: 10.1016/0006-8993(83)90152-X

Parmeggiani, P. L., Azzaroni, A., Cevolani, D., and Ferrari, G. (1986). Polygraphic study of anterior hypothalamic-preoptic neuron thermosensitivity during sleep. Electroencephalogr. Clin. Neurophysiol. 63, 289-295. doi: 10.1016/0013-4694(86)90096-9

Parmeggiani, P. L., Cevolani, D., Azzaroni, A., and Ferrari, G. (1987). Thermosensitivity of anterior hypothalamic-preoptic neurons during the waking-sleeping cycle: a study in brain functional states. Brain Res. 415, 79-89. doi: 10.1016/0006-8993(87)90270-8

Parmeggiani, P. L., Cianci, T., Calasso, M., Zamboni, G., and Perez, E. (1980). Quantitative analysis of short term deprivation and recovery of desynchronized sleep in cats. Electroencephalogr. Clin. Neurophysiol. 50, 293-302. doi: 10.1016/0013-4694(80)90157-1

Parmeggiani, P. L., Franzini, C., Lenzi, P., and Zamboni, G. (1973). Threshold of respiratory responses to preoptic heating during sleep in freely moving cats. Brain Res. 52, 189-201. doi: 10.1016/0006-8993(73)90658-6

Parmeggiani, P. L., Zamboni, G., Cianci, T., Agnati, L. F., and Ricci, C. (1974). Influence of anterior hypothalamic heating on the duration of fast wave sleep episodes. Electroencephalogr. Clin. Neurophysiol. 36, 465-470. doi: 10.1016/0013-4694(74)90203-X

Parmeggiani, P. L., Zamboni, G., Cianci, T., and Calasso, M. (1977). Absence of thermoregulatory vasomotor responses during fast wave sleep in cats. Electroencephalogr. Clin. Neurophysiol. 42, 372-380. doi: 10.1016/0013-4694(77)90173-0

Prete, F. R., Bergmann, B. M., Holtzman, P., Obermeyer, W., and Rechtschaffen, A. (1991). Sleep deprivation in the rat: XII. Effect on ambient temperature choice. Sleep 14, 109-115. doi: 10.1093/sleep/14.2.109

Rathner, J. A., and Morrison, S. F. (2006). Rostral ventromedial periaqueductal gray: a source of inhibition of the sympathetic outflow to brown adipose tissue. Brain Res. 1077, 99-107. doi: 10.1016/j.brainres.2006.01.035

Rechtschaffen, A., Gilliland, M. A., Bergmann, B. M., and Winter, J. B. (1983). Physiological correlates of prolonged sleep deprivation in rats. Science 221, 182-184. doi: $10.1126 /$ science. 6857280

Rizvi, T. A., Ennis, M., and Shipley, M. T. (1992). Reciprocal connections between the medial preoptic area and the midbrain periaqueductal gray in rat: a WGAHRP and PHA-L study. J. Comp. Neurol. 315, 1-15. doi: 10.1002/cne.903150102

Romanovsky, A. A. (2007). Thermoregulation: some concepts have changed. Functional architecture of the thermoregulatory system. Am. J. Physiol. Regul. Integr. Comp. Physiol. 292, R37-R46. doi: 10.1152/ajpregu.00668.2006

Roussel, B., and Bittel, J. (1979). Thermogenesis and thermolysis during sleeping and waking in the rat. Pflugers Arch. 382, 225-231. doi: 10.1007/BF00583706

Sakai, K., and Koyama, Y. (1996). Are there cholinergic and non-cholinergic paradoxical sleep-on neurones in the pons? Neuroreport 7, 2449-2453. doi: 10.1097/00001756-199611040-00009

Saper, C. B., Scammell, T. E., and Lu, J. (2005). Hypothalamic regulation of sleep and circadian rhythms. Nature 437, 1257-1263. doi: 10.1038/nature04284

Sapin, E., Lapray, D., Berod, A., Goutagny, R., Leger, L., Ravassard, P., et al. (2009). Localization of the brainstem GABAergic neurons controlling paradoxical (REM) sleep. PLoS ONE 4:e4272. doi: 10.1371/journal.pone.0004272

Schmidek, W. R., Hoshino, K., Schmidek, M., and Timo-Iaria, C. (1972). Influence of environmental temperature on the sleep-wakefulness cycle in the rat. Physiol. Behav. 8, 363-371. doi: 10.1016/0031-9384(72)90384-8

Schmidek, W. R., Zachariassen, K. E., and Hammel, H. T. (1983). Total calorimetric measurements in the rat: influences of the sleep-wakefulness cycle and of the environmental temperature. Brain Res. 288, 261-271. doi: 10.1016/0006-8993(83)90102-6

Sichieri, R., and Schmidek, W. R. (1984). Influence of ambient temperature on the sleep-wakefulness cycle in the golden hamster. Physiol. Behav. 33, 871-877. doi: 10.1016/0031-9384(84)90221-X

Szymusiak, R., and McGinty, D. (2008). Hypothalamic regulation of sleep and arousal. Ann. N. Y. Acad. Sci. 1129, 275-286. doi: 10.1196/annals.1417.027

Szymusiak, R., and Satinoff, E. (1981). Maximal REM sleep time defines a narrower thermoneutral zone than does minimal metabolic rate. Physiol. Behav. 26, 687-690. doi: 10.1016/0031-9384(81)90145-1

Takahashi, Y., Zhang, W., Sameshima, K., Kuroki, C., Matsumoto, A., Sunanaga, J., et al. (2013). Orexin neurons are indispensable for prostaglandin E2-induced fever and defence against environmental cooling in mice. J. Physiol. 591, 5623-5643. doi: 10.1113/jphysiol.2013.261271

Takase, K., Kikuchi, K., Tsuneoka, Y., Oda, S., Kuroda, M., and Funato, H. (2014). Meta-analysis of melanin-concentrating hormone signalingdeficient mice on behavioral and metabolic phenotypes. PLoS ONE 9:e99961. doi: 10.1371/journal.pone.0099961

Tan, C. L., Cooke, E. K., Leib, D. E., Lin, Y. C., Daly, G. E., Zimmerman, C. A., et al. (2016). Warm-sensitive neurons that control body temperature. Cell 167, 47 e15-59 e15. doi: 10.1016/j.cell.2016.08.028

Thompson, R. H., and Swanson, L. W. (2003). Structural characterization of a hypothalamic visceromotor pattern generator network. Brain Res. Brain Res. Rev. 41, 153-202. doi: 10.1016/S0165-0173(02)00232-1

Tupone, D., Cano, G., and Morrison, S. F. (2017). Thermoregulatory inversion - a novel thermoregulatory paradigm. Am. J. Physiol. Regul. Integr. Comp. Physiol. 312, R779-R786. doi: 10.1152/ajpregu.00022.2017

Tupone, D., Madden, C. J., Cano, G., and Morrison, S. F. (2011). An orexinergic projection from perifornical hypothalamus to raphe pallidus increases rat brown adipose tissue thermogenesis. J. Neurosci. 31, 15944-15955. doi: 10.1523/JNEUROSCI.3909-11.2011

Vanni-Mercier, G., Sakai, K., Lin, J. S., and Jouvet, M. (1989). Mapping of cholinoceptive brainstem structures responsible for the generation of paradoxical sleep in the cat. Arch. Ital. Biol. 127, 133-164.

Venner, A., Anaclet, C., Broadhurst, R. Y., Saper, C. B., and Fuller, P. M. (2016). A novel population of wake-promoting GABAergic Neurons in the ventral lateral hypothalamus. Curr. Biol. 26, 2137-2143. doi: 10.1016/j.cub.2016.05.078

Verret, L., Leger, L., Fort, P., and Luppi, P. H. (2005). Cholinergic and noncholinergic brainstem neurons expressing Fos after paradoxical (REM) sleep deprivation and recovery. Eur. J. Neurosci. 21, 2488-2504. doi: 10.1111/j.1460-9568.2005.04060.x

Vetrivelan, R., Kong, D., Ferrari, L. L., Arrigoni, E., Madara, J. C., Bandaru, S. S., et al. (2016). Melanin-concentrating hormone neurons specifically promote rapid eye movement sleep in mice. Neuroscience 336, 102-113. doi: 10.1016/j.neuroscience.2016.08.046

Weber, F., Chung, S., Beier, K. T., Xu, M., Luo, L., and Dan, Y. (2015). Control of REM sleep by ventral medulla GABAergic neurons. Nature 526, 435-438. doi: 10.1038/nature14979

Yoshida, K., Konishi, M., Nagashima, K., Saper, C. B., and Kanosue, K. (2005). Fos activation in hypothalamic neurons during cold or warm exposure: projections to periaqueductal gray matter. Neuroscience 133, 1039-1046. doi: 10.1016/j.neuroscience.2005.03.044

Yoshida, K., Maruyama, M., Hosono, T., Nagashima, K., Fukuda, Y., Gerstberger, R., et al. (2002). Fos expression induced by warming the preoptic area in rats. Brain Res. 933, 109-117. doi: 10.1016/S0006-8993(02)02287-4

Conflict of Interest Statement: The authors declare that the research was conducted in the absence of any commercial or financial relationships that could be construed as a potential conflict of interest.

Copyright (c) 2017 Cerri, Luppi, Tupone, Zamboni and Amici. This is an open-access article distributed under the terms of the Creative Commons Attribution License (CC $B Y)$. The use, distribution or reproduction in other forums is permitted, provided the original author(s) or licensor are credited and that the original publication in this journal is cited, in accordance with accepted academic practice. No use, distribution or reproduction is permitted which does not comply with these terms. 